\section{SANDIA REPORT}

SAND97-2397 • UC-704

Unlimited Release

Printed October 1997
RECEIVEO

NOV $1 ? 1997$

OSTI

\title{
Oriented Inorganic Thin Film Channel Structures with Uni-Directional Monosize Micropores
}

J. Cesarano III, D. Y. Sasaki, S. Singh, C. J. Brinker

Prepared by

Sandia National Laboratories.

Albuquerque, New Mexico 87185 and Livermore, Califomia 94550

Sandia is a multiprogram laboratory operated by Sandia

Corporation, a Lockheed Martin Comp. Whorme United States

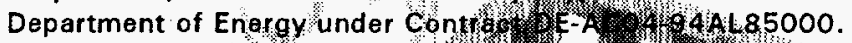

Approved for public release; further diss;

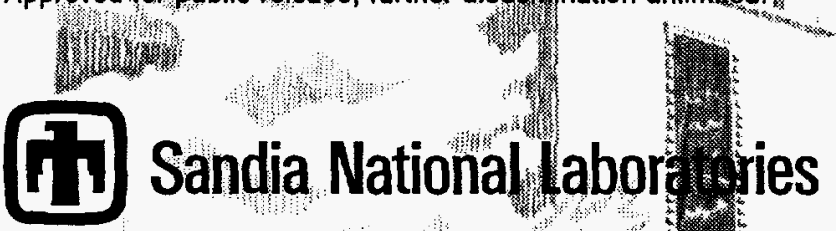

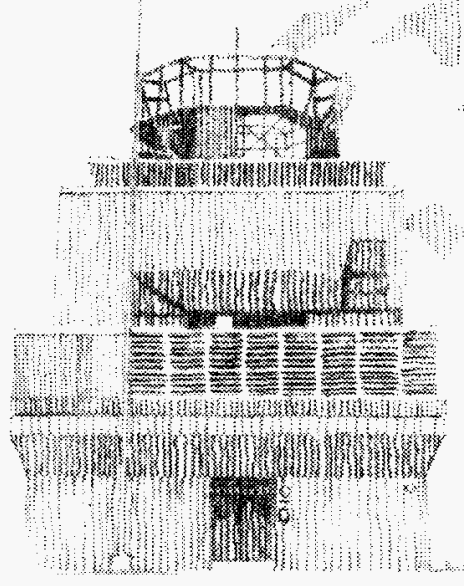

SF $29000(8-81)$
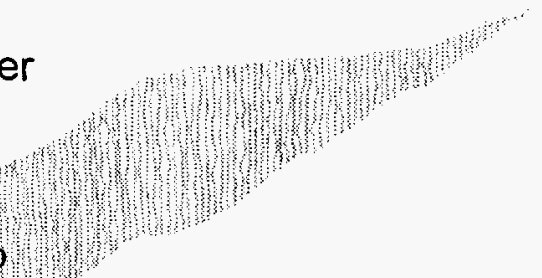


\section{DISCLAMMER}

Portions of this docament may be illegible in electronic image products. Images are produced from the best available original docoment. 
SAND 97-2397

Distribution

Unlimited Release

Printed October 1997

Category UC-704

\title{
Oriented Inorganic Thin Film Channel Structures with Uni-Directional Monosize Micropores
}

\author{
J. Cesarano III, D. Y. Sasaki, S. Singh, C. J. Brinker \\ Materials and Process Sciences Center \\ Sandia National Laboratories \\ P.O. Box 5800 \\ Albuquerque, NM 87185-1349
}

\begin{abstract}
The goal of this project was to develop a novel technology that may be used to eventually manufacture a new generation of inorganic membranes and sensors with oriented, uni-directional monosized pores. The premise is that very thin membranes with oriented channels as pores will have a high flux in addition to being highly selective. Applications include: 1) gas separation membranes for oxygen enrichment, partial oxidation, dehydrogenation, and purification of natural gas; 2) refractory catalytic membrane reactors; and 3) molecular recognition sensors.

The methodology for making such membranes was to combine Langmuir Blodgett (LB) technology with sol-gel chemistry to engineer pore channels within the range 3 to $20 \AA$. The channel structure was fabricated of amorphous $\mathrm{SiO}_{2}$ because of its good thermal, chemical, and mechanical stability. Our approach was to use LB techniques to uniformly place organic molecular spacers throughout a thin silica precursor matrix and apply this film to a substrate. LB films of solid solutions of commercially available silane amphiphiles and organic amphiphiles were fabricated. The siloxane groups were then hydrolyzed to form silica and the organic portions of the amphiphiles removed by thermal decomposition. With the completely fugitive organic spacer amphiphiles removed, a thin silica film with micropores resulted. The pore size was in the range of $6-8 \AA$ and in an ultra-thin configuration. With further development this technique may be useful for fabrication of inorganic membranes which satisfy all the criteria of the ideal membrane.
\end{abstract}




\section{SUMMARY}

The preparation of thin, supported inorganic membranes with monosized pores is currently the focus of many industrial and academic research groups. Most studies focus on development of zeolitic membranes. By virtue of their crystal structure, zeolites (generally crystalline aluminosilicate or aluminophosphate powders) exhibit monosized pores in the range 3-15 $\AA$ with 1-, 2-, or 3-dimensional connectivity. In addition, zeolites exhibit good thermal, chemical, and mechanical stability, and, thus, would appear ideal for the preparation of membranes. However, since it is not possible to sinter polycrystalline zeolites to a dense state, it has so far proven impossible to process zeolites as ultrathin defect-free films. Most processing efforts attempt to grow zeolite crystals on a porous support immersed in a gel precursor. These approaches lead to films 1-10 $\mu \mathrm{m}$ in thickness, whereas kinetic calculations suggest that practical fluxes will be only achieved for films with thicknesses below about $200 \AA$.

There have also been numerous efforts aimed at using organic templates to control pore size and shape. Some zeolite preps and the Mobil MCM-41 mesoporous materials are good examples, but, as described above, these approaches produce powders that are virtually impossible to process as thin films. Brinker, Loy and co-workers have recently used organic ligands introduced as organic-bridged silsequioxanes to create hybrid organosilicate thin films. Although pyrolysis of the template was shown to create microporosity in the film, this technique does not guarantee pore connectivity, nor are the pores likely to be 1-dimensional and oriented perpendicular to the substrate/support surface.

A practical membrane must exhibit both high flux and high chemical selectivity combined with good thermal, chemical, and mechanical stability. High flux requires a porous membrane to be thin, to contain a large volume fraction of porosity, and to exhibit low tortuosity. High chemical selectivity requires that the pores have an extremely narrow pore size distribution so that molecules are admitted or excluded from the pore channel system depending on their size - a process referred to as molecular sieving. Thermal, chemical, and mechanical stability generally require that the membrane be fabricated from an inorganic material. Based on these criteria, the ideal membrane structure would be a supported ceramic thin film $(\ll 100 \mathrm{~nm})$ exhibiting a large volume fraction of smooth, non-intersecting, monosized pores aligned perpendicular to the support surface. The goal of this project was to combine LB and sol-gel methodologies to prepare supported silica thin films exhibiting oriented uni-directional monosized pores with pore diameters in the range 3-20 $\AA$ suitable for membranes and sensors. The LB techniques yield two dimensional films, sol-gel chemistry provides conversion into thin films of silica, and organic spacers develop the idealized one-dimensional channels. 
LB films are made by transferring sequential monomolecular layers (trapped at an air/water interface) to a suitable substrate. The resulting LB structure is essentially a nanolaminate of two dimensional layers. If columnar holes were present through these layers then it is conceivable that the resulting LB film would have oriented micropores with a flow path that is essentially one dimensional. This is the idealized structure for membranes. Our challenge was to fabricate this idealized structure (with pores $3-20 \AA$ ) that is structurally sound enough (i.e., $>50 \AA$ thick) to be supported by an appropriate porous or solid substrate (depending on the application). We would like the membrane material to be amorphous $\mathrm{SiO}_{2}$ so as to be chemically and thermally stable. Feasibility relies on the ability to uniformly place columnar molecular spacers throughout a thin silica precursor matrix.

Our approach to meet this challenge required that LB films could be made with solid solutions of silane containing amphiphiles and organic molecular spacers. The resulting LB films then had to be completely hydrolyzed into silica and the molecular organic spacers removed (see Figure 1).

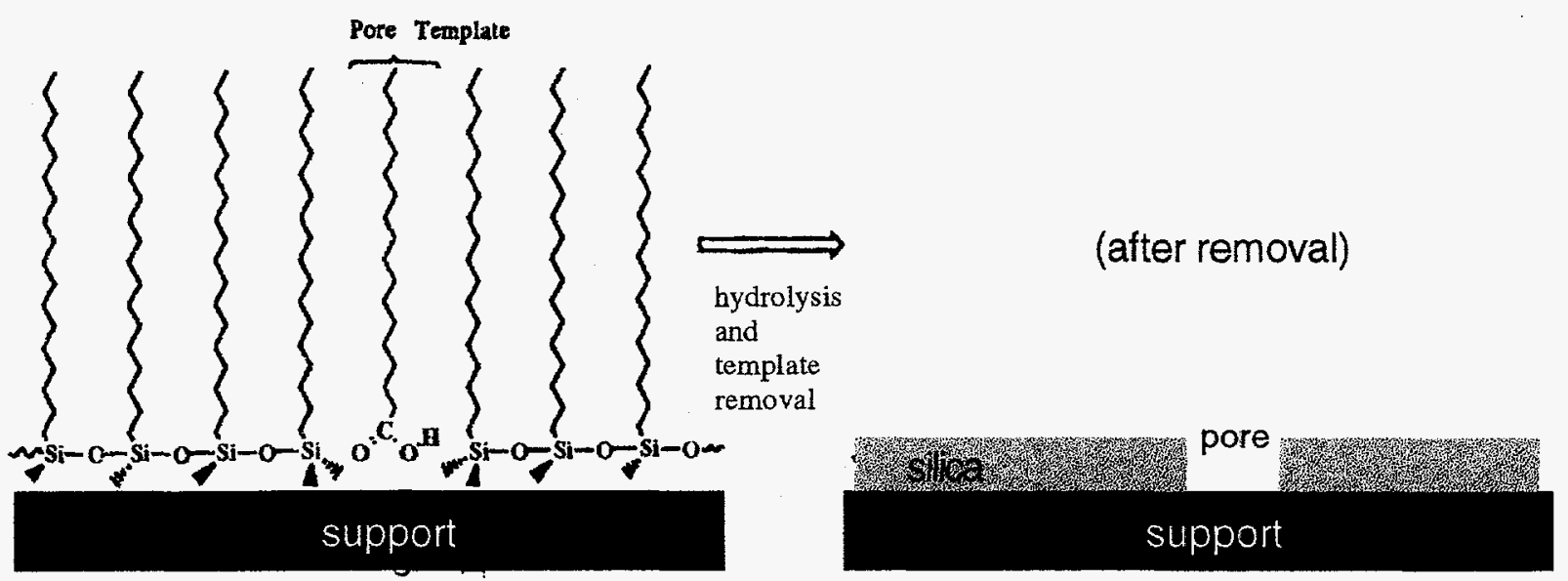

Figure 1: Schematic showing our approach to fabricate porous silica microporous cylindrical pores.

This unique approach of combining organic templates with LB silica precursors was ultimately successful in producing patterned silica films with pores in the $6-8 \AA$ range. With further development, this technique may be useful for fabricating oriented 1dimensional, monosized pores in an ultrathin film configuration, satisfying all the criteria of the ideal membrane. Details of this work are presented in Appendix A: Controlled Pore-Size Patterning in Thin Silica Film using Langmuir-Blodgett Technique. 


\section{DISCLAIMER}

This report was prepared as an account of work sponsored by an agency of the United States Government. Neither the United States Government nor any agency thereof, nor any of their employees, make any warranty, express or implied, or assumes any legal liability or responsibility for the accuracy, completeness, or usefulness of any information, apparatus, product, or process disclosed, or represents that its use would not infringe privately owned rights. Reference herein to any specific commercial product, process, or service by trade name, trademark, manufacturer, or otherwise does not necessarily constitute or imply its endorsement, recommendation, or favoring by the United States Government or any agency thereof. The views and opinions of authors expressed herein do not necessarily state or reflect those of the United States Government or any agency thereof. 


\section{Table of Contents}

Title

Abstract

1

Summary

2

Table of Contents

Appendix A: Controlled Pore-Size Patterning in Thin Silica Film

A - 1 Using Langmuir-Blodgett Technique 


\title{
APPENDIX A \\ Controlled Pore-Size Patterning in Thin Silica Film Using Langmuir-Blodgett Technique
}

\author{
Seema Singh, Darryl Sasaki, Joseph Cesarano III
}

\begin{abstract}
Controlled pore size materials are currently the focus of many research groups. Potential applications of controlled pore size films exist in gas separation, sensor materials and catalysis. In this communication, our approach to pattern ultrathin silica films with oriented, unidirectional, nano-scale pores are described. Using the LangmuirBlodgett technique we have fabricated hybrid octadecyl trimethoxy siloxane monolayer network with dispersed octadecyl trimethoxy sulfonate sodium salt. We have shown that by removing the organic spacers through pyrolysis, patterned silicate materials of 7-9 $\AA$ thickness with pore-size ranging from $8 \AA$ to $125 \mathrm{~nm}$ can be created. Furthermore, our study of the mechanical stiffness of these siloxane films indicates its potential application as antistiction coating for micromechanical parts.
\end{abstract}

\section{Introduction}

Recently, there has been great interest in developing methods to tune the pore size of materials for the purpose of molecular sieving. 1,2 The molecular sieving process, which excludes or admits molecules depending on the size, has been implemented in many different fields. For example, controlled pore size films have potential application in gas separation ${ }^{3-7}$, sensor materials $8,9,10$ and catalysis. Methods to create porous inorganic materials include sol-gel techniques $11-15$, chemical vapor deposition $16-17$, and zeolitic approach 18-20. The sol-gel process is the most popular technique due to facile room temperature fabrication, however pore size control remains a problem. Zeolites exhibit good thermal, chemical, and mechanical stability and because of their crystalline structure exhibit monosized pores. However, it is not possible to sinter polycrystalline zeolites to a dense state. It has so far been impossible to process zeolites as ultrathin defect free films 21 . Furthermore, for the aforementioned applications, interest in patterning thin films has generated a variety of different techniques. Methods for thin film patterning reported in the literature include electrochemical etching 22-24, laser ablation ${ }^{25}$, biomimetics ${ }^{26}$, tip-assisted STM $^{27}$ among others. These methods have 
enabled patterning of a variety of substrates from self-assembled monolayers to electronic circuits.

In this paper, we report a Langmuir-Blodgett approach 28-30 to create patterned structures in porous ultra thin silica films. Our interest in controlled pore-size patterning is two folds; first we are interested in developing methods to pattern ultrathin silica films for sensor materials; second, we wish to fabricate inorganic membranes with oriented, unidirectional monosized pores for permselective membranes. Due to their good chemical, thermal, and mechanical stability, we have chosen inorganic $\mathrm{SiO}_{2}$ films in our studies. Our approach to pattern thin silica films and to fabricate monosized nano-scale pores is made possible by using commercially available silane and organic amphiphiles to fabricate Langmuir-Blodgett films on a solid support. After subsequent condensation of the siloxane amphiphiles, the organic spacers are removed leaving behind a patterned structure and oriented unidirectional monosized pores.

\section{Experimental}

\subsection{Materials:}

Octadecyl trimethoxy silane (OTMS) and octadecyl trimethoxy sodium sulfonate salt (OSS) were obtained from Aldrich. OTMS was purified by low pressure distillation and OSS was recrystallized three times in ethanol prior to use. 12-nitrobenzoxadiazole octadecanoic acid (12-NBD stearic acid) was purchased from Molecular Probes Inc. (Eugene, OR) and used without further purification. Anhydrous benzene was obtained from Aldrich. All other solvents used were of HPLC grade.

For monolayer preparation, ultrapure (organic free deionized, resistivity $>18$ $\mathrm{M} \Omega / \mathrm{cm}$ ) water was obtained using a Millipore reverse osmosis/ion-exchange system (Milli Q Plus). Monolayers were deposited on silicon/SiO 2 or freshly cleaved mica substrates. Silicon wafers ( $1 / 2$ " $\times 1 / 2$ " dies) were purchased from Silicon Source Technology, Corp. (Tempe, Arizona) and were cleaned with a Micro-Plasma series 900 plasma cleaner (Technics, Inc.) at -35 watts for 10 minutes in the presence of oxygen, prior to use. This treatment gives a $\mathrm{Si} / \mathrm{SiO}_{2}$ surface that was completely wetted by water. All the glassware used were cleaned in piranha solution $\left(70: 30 \mathrm{H}_{2} \mathrm{SO}_{4} / \mathrm{H}_{2} \mathrm{O}_{2}\right)$ and rinsed thoroughly with ultrapure water.

Formation of Pure OTMS and mixed OTMS/OSS monolayers and Langmuir Blodgett (LB) Films. Monolayer spreading solutions were prepared in $20 \%$ DMSO/anhydrous benzene. Typical solutions were prepared 1-2 mg/ml. A Nima Technology Ltd., model 2011 circular Langmuir trough (Coventry, England) was used. 
Acidic $(0.01 \mathrm{~N} \mathrm{HCl})$ and basic $(0.01 \mathrm{~N} \mathrm{NaOH})$ subphases were also used to catalyze the hydrolysis and condensation reactions of the siloxanes. Before each experiment the water surface was compressed and cleaned. Following spreading the monolayers were incubated at zero pressure for approximately $20-40$ minutes. The $\pi$-A isotherms were obtained at room temperature with a compression speed of $50 \mathrm{~cm}^{2} / \mathrm{min}$. For Langmuir Blodgett supported film, a deposition rate of $1 \mathrm{~mm} / \mathrm{min}$ was used. LB films were transferred on the upstroke at constant surface pressure of $25-30 \mathrm{mN} / \mathrm{m}$ for both mica and $\mathrm{Si} / \mathrm{SiO}_{2}$ (hydrophilic surfaces). Surface pressure, measured using a Wilhelmy plate, showed fairly constant pressure $( \pm 0.5 \mathrm{mN} / \mathrm{m})$ during LB deposition.

To visualize patterned structures in the supported monolayer, fluorescence microscopy was used to view LB films of siloxane/organic amphiphile monolayers with $1 \% 12-\mathrm{NBD}$ probe. To ensure complete condensation (Si-O-Si crosslinks formation in this case), all the supported LB films were cured overnight at $80-101^{\circ} \mathrm{C}$ in a furnace in the presence of oxygen. For the removal of organic spacers, LB films were pyrolyzed by heating in a furnace by gradually increasing to the temperature and maintaining the final desired temperature for 8-10 hours.

\subsection{Ellipsometry:}

Thicknesses of the siloxane and mixed siloxane/organic deposited monolayers on single crystal silicon wafers were measured before and after pyrolysis using a GAERTNER model L116C ellipsometer, equipped with He-Ne laser light source (beam wavelength $632.8 \mathrm{~nm}$ ) at an incident angle of $70^{\circ}$. The instrument was calibrated using a standard. Reported values are an average of seven measurements taken at different spots on each sample.

\subsection{Contact angle measurements:}

For contact angle measurement, a VCA-200 (Advanced Surface Technology, Inc., Bellerica, MA) sessile drop system with a video monitor and tilting sample stage was used. Water contact angles were measured for the substrates, pure OTMS and mixed OTMS/OSS LB films before and after pyrolysis. All the reported contact angles are averages of five different measurement on each sample.

\subsection{Microscopy:}

Scanning Force Microscopy (SFM) of supported OTMS and mixed OTMS/OSS LB Films. Nanoscope II SFM instrument (Digital Instruments, Santa Barbara, CA) was used to characterize the supported LB films of OTMS and mixed OTMS/OSS on $\mathrm{Si} / \mathrm{SiO}_{2}$ and freshly cleaved ruby mica. Beside looking at topography, we used the SFM to measure film thickness and roughness. In addition, mechanical stability and rigidity of the films were also assessed. For these purposes, a silicon nitride cantilever with 
integrated silicon nitride pyramidal tips were used. The unaltered tip had an average radius of curvature of $50 \mathrm{~nm}$. SFM tips with spring constants ranging from $.06 \mathrm{~N} / \mathrm{m}$ to $.56 \mathrm{~N} / \mathrm{m}$ were used. Imaging was done in the constant force mode with set-point voltage adjusted to minimize the force between the tip and the sample.

\subsection{Molecular Mechanics Calculation:}

Molecular energy optimization calculations were performed using Discover software (Molecular Simulations, Inc.). ESFF force field was used to estimate the thicknesses of the LB films for comparison with the experimental data.

\section{Results and Discussion}

Typical pressure-area $(\pi-\mathrm{A})$ isotherms for pure OTMS and mixed OTMS/OSS amphiphile Langmuir monolayers on water subphase are shown in Figure 1. A pure OTMS monolayer on pure water shows highly expanded behavior with two transitions. One transition at $45 \AA^{2}$ and the other at $28 \AA^{2}$. Lift off pressure (i.e., the first measurable pressure increase) occurs at $63 \AA^{2}$. The liquid-solid coexistence region can be seen from $23-45 \AA^{2}$. For pure OTMS monolayers, collapse occurs at a pressure above $30 \mathrm{mN} / \mathrm{m}$. The pressure-area isotherm of OTMS with different mole fractions of OSS are also shown in figure 1. The effect of incorporation of small amounts of OSS in the siloxane amphiphile monolayer can be seen in the resulted condensed isotherms. The extrapolated limiting area for the pure OTMS film is about $20 \AA^{2}$ which is close to the calculated area occupied by the molecule.

Monolayers were prepared on aqueous subphases with different $\mathrm{pHs}$ and examined for film quality. Three main criterion were examined for film quality: high transfer ratio, surface coverage, and homogeneity. The transfer ratio was found to be dependent on the rate of deposition, $\mathrm{pH}$ of the subphase, and hydrophilicity of the subphase. The transfer ratios were highest $(\sim 1)$ from pure water subphase and good from acidic $(0.01 \mathrm{M} \mathrm{HCl})$ subphase. Poor transfer ratios were observed from the basic $0.01 \mathrm{M}$ $\mathrm{NaOH}$ subphase. The poor deposition may be due to ionic repulsion between the highly negative charged sulfonate and silicate monolayer and the solid substrates. On pure water and acidic subphases, the monolayers exhibited solid phase behavior above $20 \mathrm{mN} / \mathrm{m}$ showing that the amphiphiles can achieve a close packed configuration at high pressures. However, on basic $(0.01 \mathrm{M} \mathrm{NaOH})$ subphase the monolayers are expanded even at high pressures. This would be consistent with ionic repulsion between the siloxane and sulfonate headgroups. 


\section{Pressure-Area Isotherms}

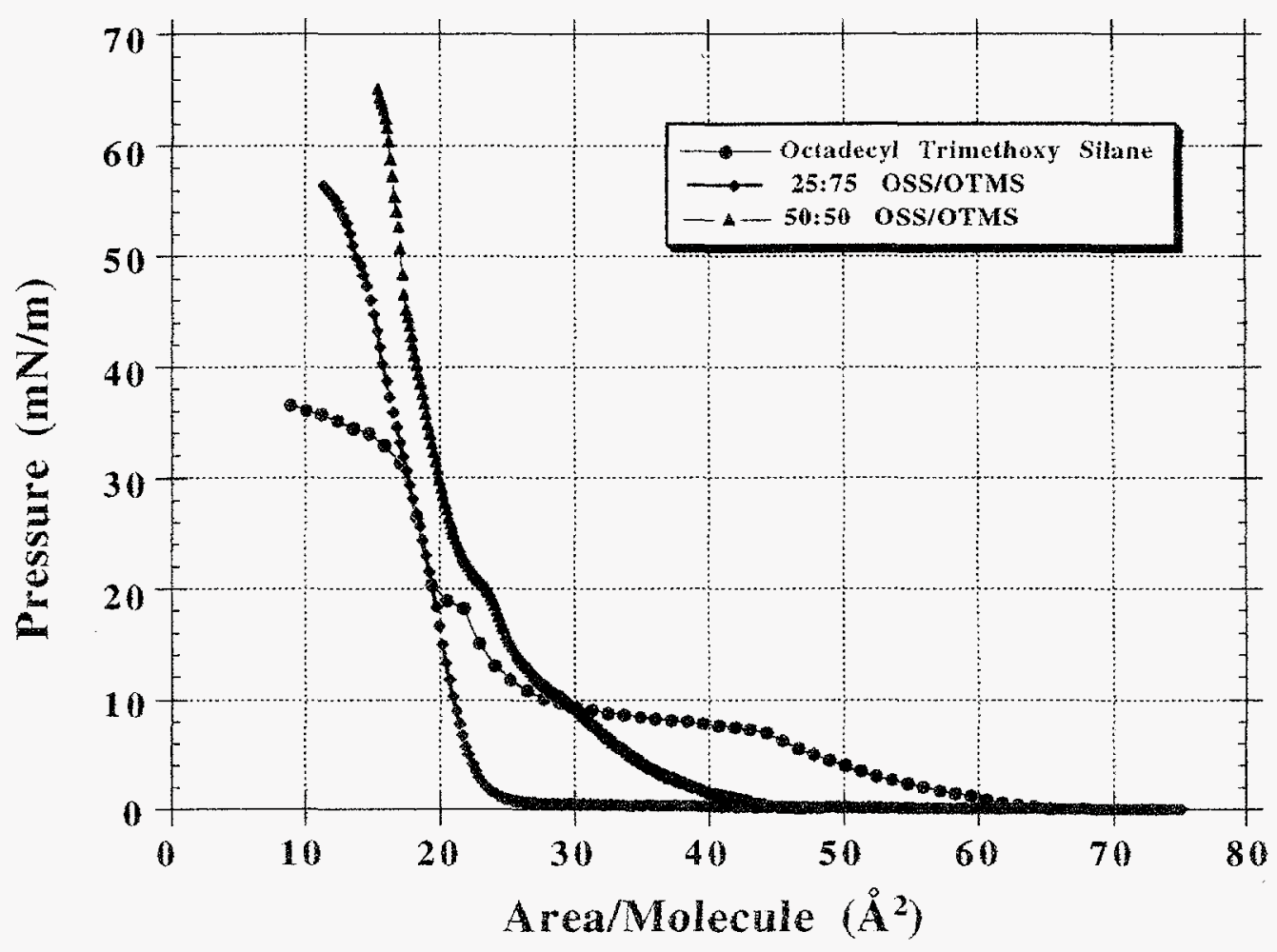

Figure 1: Surface pressure-area $(\pi$-A) isotherms for pure OTMS, 25:75 OSS/OTMS and 50:50 OTMS/OSS on water subphase at room temperature. Pure OTMS monolayer shows highly expanded behavior with two transitions (liquid expanded and liquid condensed). The 25:75 OSS/OTMS on the other hand shows only a condensed isotherm. Collapse pressure of pure OTMS, 25:75 OSS/OTMS, and 50:50 OSS/OTMS are 32, 54 and $65 \mathrm{mN} / \mathrm{m}$, respectively (Barrier speed $=50 \mathrm{sq} . \mathrm{cm} / \mathrm{min}$ ).

Figure 2 shows SFM images of OTMS LB films transferred from pure water, acidic, and basic subphases on a $\mathrm{Si} / \mathrm{SiO}_{2}$ substrate deposited at constant pressure of 27 $\mathrm{mN} / \mathrm{m}$. With minimum loading force, the images clearly show that from a pure water subphase the LB film is homogeneous with good coverage. From the acidic subphase, again the LB film is homogeneous but the surface coverage is slightly poorer compared to the film from the water subphase. The monolayer from the basic subphase is very heterogeneous. 

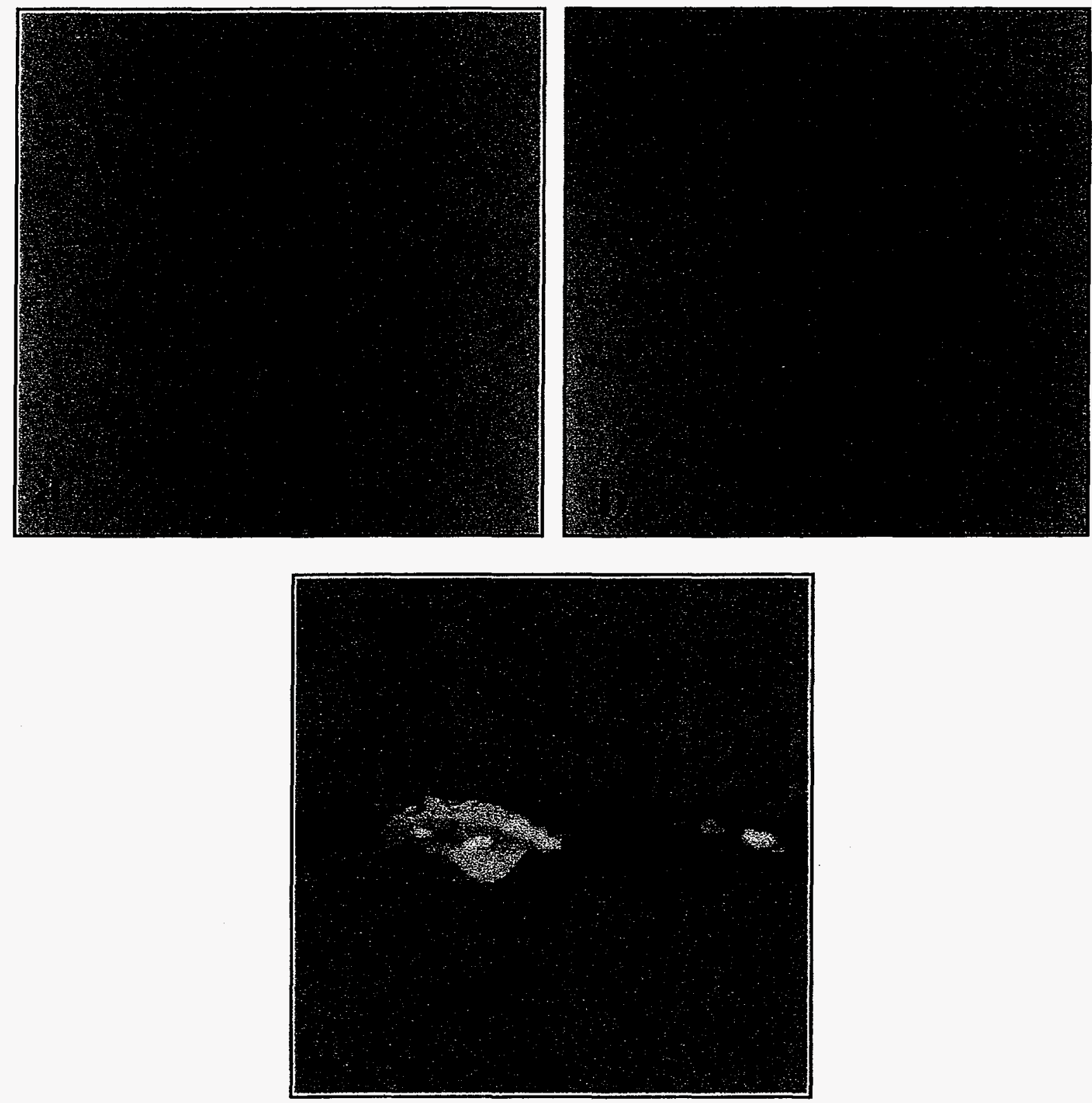

Figure 2: Topographical AFM images of OTMS monolayers transferred onto silicon wafer to show the effect of subphase composition on the film quality. LB films transferred from a) pure water $(6631 \times 6631 \mathrm{~nm})$, b) $0.01 \mathrm{M} \mathrm{HCl}$ ( $13439.90 \times 13439.90 \mathrm{~nm}$ ), and, c) $0.01 \mathrm{M} \mathrm{NaOH}(3486.44 \times 3486.44 \mathrm{~nm})$. 
To ensure that silane and organic amphiphiles do not phase separate in the monolayer, the films were doped with nitrobenzoxadiazole labeled stearic acid (12-NBD stearic acid), and examined through fluorescence microscopy. The images showed background fluorescence instead of domain formation, as would be expected for immiscible amphiphiles. Supported LB films with different mole fractions of OTMS/OSS (5\%,15\% and 50\%) doped with fluorescent probe could not detect domain formation at 5 and 15\% OTMS/OSS. In contrast, the 50\% OTMS/OSS showed domain formation with diameters of $5000-8000 \mathrm{~nm}$ indicating phase separation. Miscibility of the amphiphiles was also checked by plotting collapse pressure vs mole fraction of OTMS/OSS. The plot showed linear behavior between a minimum $(32 \mathrm{mN} / \mathrm{m})$ for pure OTMS and maximum $(65 \mathrm{mN} / \mathrm{m})$ for pure OSS.

Thicknesses of the pure OTMS and mixed OTMS/OSS LB films supported on $\mathrm{Si} / \mathrm{SiO}_{2}$ substrates were measured using ellipsometry and scanning force microscopy. Ellipsometry measurements on supported OTMS LB films after curing at $80^{\circ} \mathrm{C}$, gave an average thickness of $22.57 \AA$. The same supported OTMS LB film after pyrolysis showed a film thickness of about $7 \AA$. This indicates, and is consistent with, the successful removal of organic spacers including the hydrocarbons from OTMS. A calculated film thickness (Figure 3) of $23.08 \AA$ from molecular mechanics of OTMS and OTMS/OSS LB films shows good agreement with the ellipsometry data. Additionally, film thickness for OTMS was measured by SFM to be $22.58 \AA$ by taking a cross-section line profile and measuring the height from the top of the film to the top of the substrate.

To show the pores created by pyrolysis, SFM images were taken of the pure OTMS and mixed OTMS/OSS films after pyrolysis. The surface plot for $11 \%$ OSS/OTMS is shown in figure 4c. SFM data for $11 \%$ OSS/OTMS supported LB film seem to indicate the porous film with pore size ranging from 6-8 $\AA$. The pores are approximately 5-7 $\AA$ deep and not very homogeneous. With an $11 \%$ spacer content there seems to be too many amphiphiles for the pores to be well separated. As a result, oftentimes the pores look to be connected side-ways. In contrast with 11\% OTMS/OSS film, pure OTMS film after pyrolysis did not show these features (figure 4b). This suggests that the patters are due to amphiphiles in the siloxane LB film. To prove the hypothesis, that these patterns are created in fact by the spaces left by the organic spacers, two other mole fractions of OSS/OTMS (25\% and 50\%) were tested. Topographical SFM image of $25 \%$ OSS/OTMS after pyrolysis is shown in figure $4 \mathrm{~d}$. The $25 \%$ OSS/OTMS film shows patterned film with features indicating pores of $125 \mathrm{~nm}$ in size. In this case, pores are very homogeneous in size. Pattern seem more circular in shape and well separated. On the other hand, 50\% OSS/OTMS film (data not shown here) shows huge pores indicating phase separation with very large domain separation. Measured size of the valley was about few thousands nanometer. This phase separation was also evident 
from fluorescence microscopy visualization of the 50\% OSS/OTMS LB film. These results suggest that it is possible to crate pattern structure in thin silica film using very simple approach as LB technique. The drawback of our approach is that we have limitation over the pattern size. Nonetheless, this method does allow the precise control on patterning film at few angstrom level. Also, using the same concept, the shape of the molecule could also be varied to create the pattern of different shape in thin silica films.
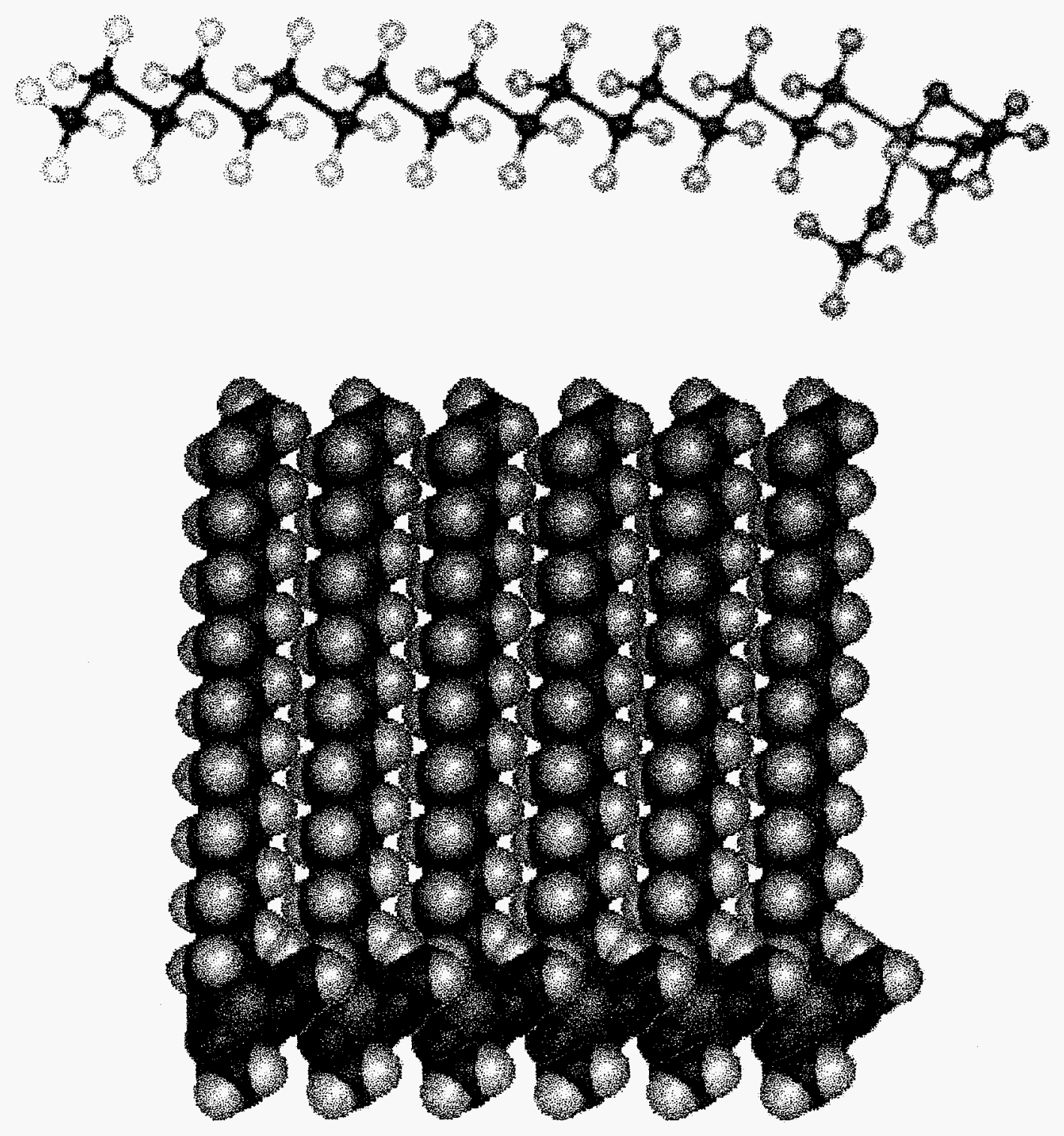

Figure 3: Energy optimized structure of octadecyltrimethoxysilane molecule. Carbon, hydrogen, silicon and oxygen atoms are displayed in green, white, pink and red, respectively. Molecular mechanics calculation of siloxane monolayer gave an average thickness of $23.08 \AA$ for Langmuir-Blodgett monolayers. 

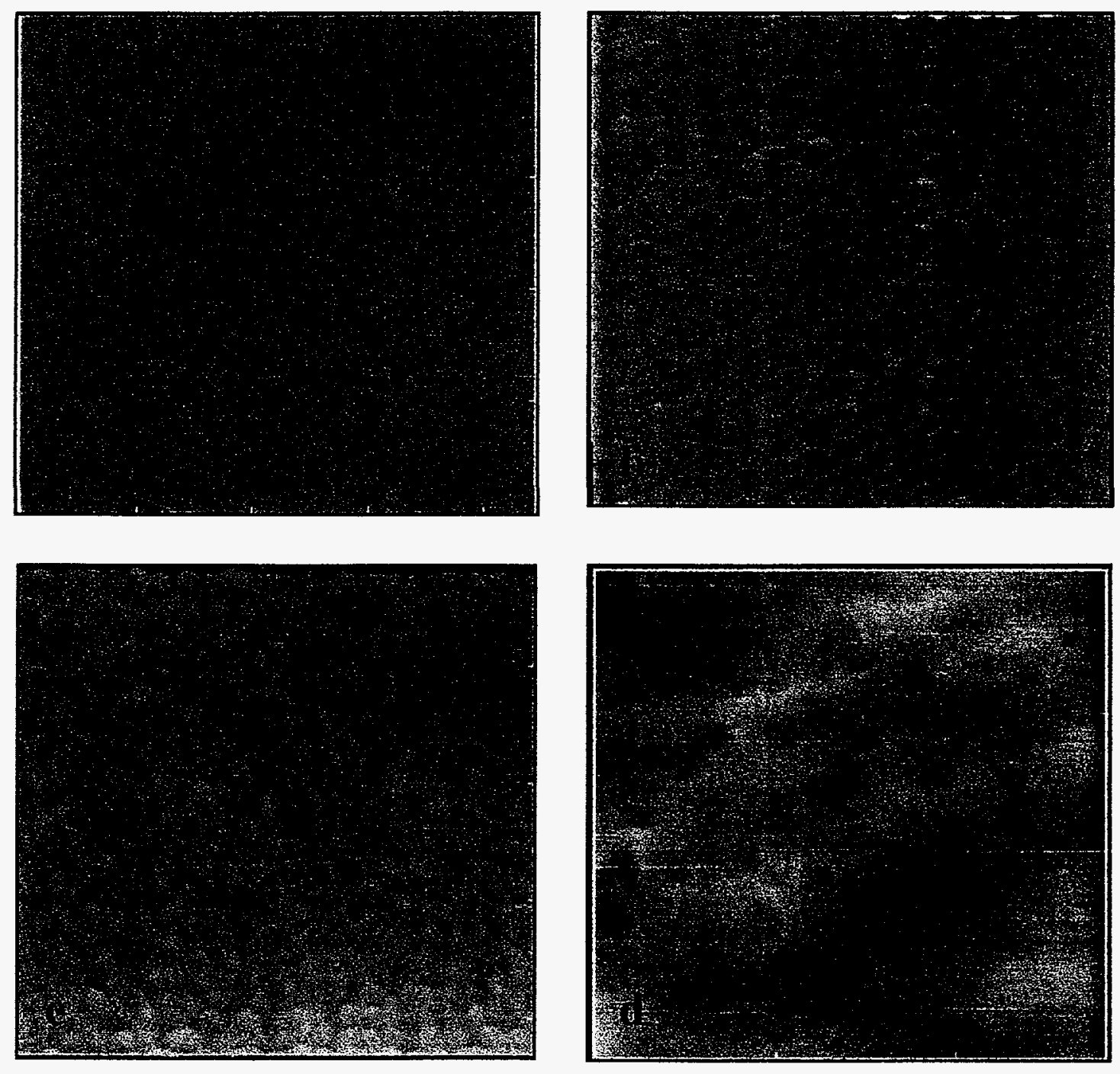

Figure 4: $\quad$ Contact mode AFM images of monolayers transferred on plasma cleaned silicon wafer on upstroke after pyrolysis. a) Pure OTMS, b) $11 \%$

OSS/OTMS and c) $25 \%$ OSS/OTMS. The image size is a) $8.7 \times 8.7 \mathrm{~nm}$, b) $8.7 \times 8.7 \mathrm{~nm} \mathrm{c)} 1400 \times 1400 \mathrm{~nm}$. Pure OTMS shows no porous features, $11 \%$ OSS/OTMS shows pores of 6-8 $\AA$ in size, and $25 \%$ OSS/OTMS shows pores of $\sim 125 \mathrm{~nm}$ in size. 

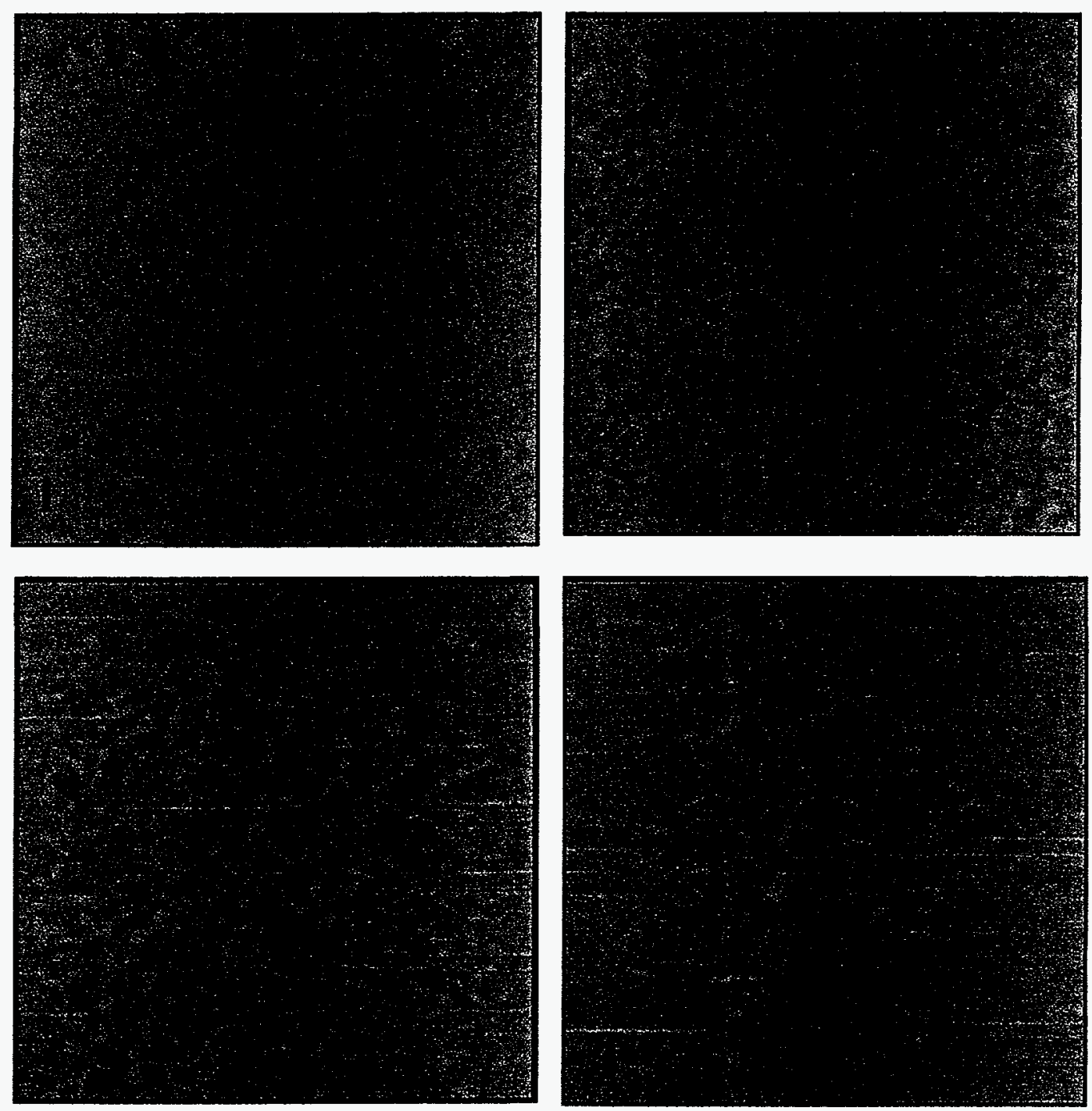

Figure 5: Series of topographical atomic force micrographs of stearic acid monolayer transferred on silicon substrate showing damage to the monolayer created by loading force during scanning. The elapse time is approximately 10 minutes. Silicon nitride cantilever with nominal spring constant $0.06 \mathrm{~N} / \mathrm{m}$ was used. Imaging was done in air. Siloxane monolayer on the other hand shows no sign of damage even with stiff cantilevers.

For other applications of these films, for example its use as a hydrophobic antistiction coating, mechanical stiffness and rigidity of the OTMS LB films transferred to $\mathrm{Si} / \mathrm{SiO}_{2}$ substrate were determined. The supported OTMS film was found to be very stable for months. SFM cantilevers with spring constant ranging from $0.06 \mathrm{~N} / \mathrm{m}-0.58$ $\mathrm{N} / \mathrm{m}$ were used to damage the LB film during imaging. It was not possible to damage supported siloxane monolayer with forces up to millinewton range. To test the factors 
influencing film toughness, for example, hydrocarbon chain and polymerization/crosslinking to the substrate, supported stearic acid films were examined similarly. While it was not possible to damage the OTMS film, supported stearic acid films could very easily be damage even with the soft $(0.06 \mathrm{~N} / \mathrm{m})$ cantilevers. Figure 5 shows a series of topographical SFM images showing damage in progress from one scan to the next. The total time elapsed was 10 minutes. The monolayer damage is readily seen as the tip sweeps the monolayer from the substrate. Since the OTMS and Stearic acid films both have same chain length hydrophobic portion, we conclude that the mechanical stiffness for OTMS film is due to its crosslinking to the substrate and to a greater extent from polymerization of siloxane.

\section{Conclusions}

We have demonstrated for the first time a novel method of fabricating patterned thin films using Langmuir-Blodgett technique. To our knowledge, thin film patterning using simple Langmuir-Blodgett technique has not been reported. We showed that, in general for antistiction coating purposes, siloxane films are more mechanically stable than similar chain length fatty acids. Furthermore, OSS amphiphile does not pool into domains in an OTMS matrix provided that the concentration is below $25 \%$ of OTMS amphiphiles.

Currently, we are trying to characterize the film porosity in order to assess the usefulness of the film as a membrane for gas separation using impedance and permeability measurements.

\section{Acknowledgments}

A special thanks goes to Alan J. Hurd, Manager of the Theoretical and Computational Materials Modeling Department.

Sandia is a multiprogram laboratory operated by Sandia Corporation, a Lockheed Martin Company, for the United States Department of Energy under Contract DE-AC0494AL85000. S.S would like to thank Charles Pacheco for help with sample preparation. 


\section{References}

1. Way, J. D.; Roberts, D. L. Sep. Sci. Technology. 1992, 27, 29.

2. Hassan, M. H.; Way, J. D.; Thoen, P. m.; Dillon, A. C. J. Membr. Sci. 1995, 104, 27.

3. Inorganic Membranes: Synthesis, Characterization and Properties (Ed: R Bhave), Van Nostrand Reinhold, New York 1991.

4. Anderson, M. A.; Gieselmann, M. J.; Xu, Q. J. Membr. Sci. 1988, 39, 243.

5. Larbot, A.; Fabre, J. P.; Guizard, C.; Cot, L. J. Membr. Sci. 1988, 39, 203.

6. Leenaars, A. F. M.; Keizer, K.; Burggraff, A. J. J. Mater. Sci. 1984, 19, 1077.

7. Goldsmith, R. L. J. Membr. Sci. 1990. 39, 197.

8. Lin, Y. S.; Burggraaf, A. J. AIChE J. 1992, 38, 445.

9. Gavalas, G. R.; Megiris, C. E.; Nam, S. W. Chem. Eng. Sci . 1989, 44, 1829.

10. Cao, G. Z.; Brinkman, H. W.; Meijerink, J.; De Vries, K.J.; Buggraaf, A. J. J. Mater. Chem. 1993, 76, 2201.

11. Brinker, C.J; Sherer, G.W. Sol-Gel Science: The Physics and Chemistry of Sol-Gel Processing, Academic Press, San Diego, CA 1990.

12. Gavalas, G.R.; Megiris, C.E.; Nam, S.W. Chem. Eng. Sci. 1989, 44, 1829.

13. Cao, G.Z.; Brinkman, H.W.; Meijerink, J.; De Vries, K.J.; Buggraaf, A.J.J. Mater. Chem. 1993, 76, 2001.

14. Brinker, C.J.; Sehgal, R.; Hietala, S. L.; Despande, R.; Smith, D.M.; Loy D.; Ashley, C.S. J. Membr. Sci. 1994, 94, 85.

15. Raman, N.K.; Anderson, M.T.; Brinker, C.J. Chem. Mater. 1996, 8, 1682.

16. Lin, Y.S.; Burggraaf, A.J. AlChE J. 1992, 38, 445.

17. Ott, A.W.;Klaus,J.W.; Johnson, J.M.; George, S.M. Chem. Mater. 1997, 9, 707.

18. Morooka, S.; Kusakabek, K.; Kuruda, T. Industrial engineering chemistry research $1997,36,649$.

19. Kyotani, T.; Nagai, T.; Tomita, A. Chemistry of materials 1997, 9, 609 .

20. Kusakabe, K.; Murata, A.; Morooka, S. J. Membr. Sci. 1996, 116, 39.

21. Geus, E. R.; den Exter, M. J.; van Bekkum, H. J. Chem. Soc. 1992, 88, 3101.

22. Chan, K.C.; Kim, T.; Schoer, J.K.; Crooks, R.M.J . Am. Chem. Soc. 1995, 117, 5875.

23. Kaindl, J.; Sotier, S.; Franz, G. J. of the electrochemical society 1995, 142, 2418.

24. Georgiadou, M.; Alkire, R. J. of the electrochemical society 1994, 141, 679.

25. Lopez, G.P.; Tender, L. M.; Worlery, R. L. Langmuir 1996, $12,5515$.

26. Tanev, P.T.; Pinnavaia, T.J. Science, 1996, 271, 1267.

27. Day, H.C.; Allee, D.R.; George, R.; Burrows, V.A. Appl. Phys. Lett. 1993, 62, 1629.

28. Ulman, A. An Introduction to Ultrathin Organic Films, From Langmuir Blodgett to Self-Assembly: Academic Press: Boston, MA, 1991.

29. Ulman, A. Adv. Mater. 1990, 2, 573.

30. Roberts, G. Langmuir-Blogett Films, Plenum Press: New York, 1990. 


\section{DISTRIBUTION:}

$\begin{array}{lll}5 & \text { MS-1349 } & \text { J. Cesarano } \\ 3 & \text { MS-1407 } & \text { D. Sasaki } \\ 3 & \text { MS-1405 } & \text { S. Singh } \\ 3 & \text { MS-0333 } & \text { A. Hurd } \\ 1 & \text { MS-1349 } & \text { C. J. Brinker } \\ 1 & \text { MS-1411 } & \text { C. Ashley } \\ 1 & \text { MS-0710 } & \text { T. Gardner } \\ 1 & \text { MS-0710 } & \text { T. Nenoff } \\ 1 & \text { MS-0710 } & \text { A. Sylwester } \\ 1 & \text { MS- 9018 } & \text { Central Technical Files, 8940-2 } \\ 5 & \text { MS-0899 } & \text { Technical Library, 4916 } \\ 2 & \text { MS-0619 } & \text { Review \& Approval Desk, 12690 } \\ & & \text { For DOE/OSTI } \\ 1 & \text { MS-0161 } & \text { Patent and Licensing Office, 11500 }\end{array}$

